\title{
A CULTURA JURÍDICA PROCESSUAL CIVIL BRASILEIRA NA SEGUNDA METADE DO SÉCULO XIX: UMA ANÁLISE À LUZ DAS OBRAS DE FRANCISCO DE PAULA BATISTA E JOAQUIM IGNÁCIO RAMALHO
}

\author{
BRAZILIAN LEGAL CULTURE AND THE CIVIL PROCEDURE IN THE SECOND
}

HALF OF THE NINETEENTH CENTURY: AN ANALYSIS BASED ON THE WORKS

OF FRANCISCO DE PAULA BATISTA AND JOAQUIM IGNÁCIO RAMALHO

Bruno Marzullo Zaroni*

\begin{abstract}
Resumo: O presente artigo pretende analisar o perfil da cultura jurídica processual em formação no Brasil na segunda metade do século XIX. Por cultura jurídica devem ser entendidos determinados padrões e significados (doutrinários ou de interpretação) que transitavam e produziam efeitos nas instituições jurídicas, atribuindo certas propriedades ao direito brasileiro. Para tanto, o presente ensaio centrará seus esforços na análise do pensamento e das obras dos lentes da cadeira de direito processual civil nas faculdades de direito do Império (Recife e São Paulo), Francisco de Paula Batista e Joaquim Ignácio Ramalho, e que eram empregadas no ensino jurídico.
\end{abstract}

Palavras-chave: Cultura jurídica brasileira. Ensino jurídico. História do direito. Direito processual civil.

Abstract: The paper aims to understand the profile of the Brazilian legal culture concerning the civil procedure in the second half of the nineteenth century. By legal culture, it must be understood certain patterns and meanings (doctrinal or arising from interpretation) which transited and produced effects on the legal institutions, engendering certain features to the Brazilian law. For this purpose, based on a historical methodology, the article will focus its efforts on the analysis of the thought and the handbooks of the leading scholars of civil procedure in the law schools of Recife and São Paulo, Francisco de Paula Batista e Joaquim Ignácio Ramalho.

Keywords: Brazilian legal culture. Legal education. Legal history. Civil procedure.

\section{INTRODUÇÃO: PREMISSAS METODOLÓGICAS E OBJETIVO}

No período colonial, o processo civil brasileiro era integralmente regido pelas normas portuguesas (FAORO, 1987, p. 22). Mesmo com a independência do país, em 1822, manteve-se, por força da Lei de 20 de outubro de 1923, em vigor no Brasil toda a legislação portuguesa. Assim, o processo civil, no início da época imperial, era regido especialmente pelo Livro III das Ordenações Filipinas, com as alterações promovidas por normas esparsas, notadamente a Lei da Boa Razão, de 18 de agosto de 1769.

Este vínculo de dependência em relação à antiga metrópole revelava-se igualmente presente no tocante ao ensino e formação do pensamento jurídico, o que se justifica pela inexistência à época de faculdades de direito no Brasil (resultando na formação

\footnotetext{
* Doutorando e Mestre em Direito pela UFPR. Pesquisador do Núcleo Pesquisa História, Direito e Subjetividade e do Núcleo de Direito Processual Civil Comparado, ambos do PPGD/UFPR. Professor de Direito Processual Civil da Universidade Positivo. Advogado.
} 
portuguesa dos primeiros bacharéis) e, por conseguinte, pelo emprego do arcabouço doutrinário-jurídico português.

Com a promulgação do Código de Processo Criminal do Império, em 1832, que continha como anexo a Disposição Provisória acerca da Administração da Justiça Civil, o sistema processual sofreu tímida tentativa de emancipação, embora ainda insuficiente para estabelecer um modelo distinto e independente da tradição lusitana (COSTA, 1970, p. 5-6).

Um verdadeiro "Código" de Processo Civil nunca foi criado na era imperial, o que fez com que as Ordenações fossem aplicadas até 1850, quando foi promulgado o Regulamento 737, que disciplinou o processo das causas de natureza comercial e cuja aplicação foi estendida (com certos ajustes) às causas cíveis pelo Decreto 763, de 1890 (LIEBMAN, 1962, p. 500).

Para alguns, é nesse contexto histórico de tensão e ruptura, notadamente a partir de estudos científicos sobre o referido Regulamento 737 e da fundação dos cursos jurídicos no Brasil, que teria florescido a doutrina processual civil brasileira. (BUZAID, 1982; COSTA, 1970)

Nada obstante tal afirmação, raros são os estudos que busquem, a partir de uma perspectiva historiográfica, compreender o perfil do pensamento jurídico processual brasileiro da segunda metade do século XIX ou identificar uma cultura jurídica relativa ao direito processual civil neste período.

Não raro alude-se genericamente a um contínuo processo evolutivo da disciplina, com sua formulação à luz de bases científicas - associada, na maioria das vezes, à influência de teorias estrangeiras, tal como a "Teoria das Exceções Dilatórias e dos Pressupostos Processuais", de Oscar Von Bülow, no ano de 1868; ou o estudo sobre o caráter publicista do processo, de Giuseppe Chiovenda, publicado em 1903 -, mas sem maior atenção à cultura processual brasileira à luz do contexto social, político e ideológico vivenciado neste intervalo histórico de transição.

É como se a cultura jurídica processual civil brasileira tivesse despontado a partir da influência de tais referenciais teóricos, o que implica em se olvidar de um período crucial na formação das bases culturais do direito processual civil.

Corre-se o risco, portanto, nesta perspectiva de análise - por vezes superficial e simplificadora - do pensamento jurídico, de se atribuir a este saber e seus elementos um caráter atemporal, de destituí-lo enquanto fenômeno cultural de sua historicidade; arrisca-se, ainda que o resgate histórico seja "uma mera recuperação vazia e inócua dos dados pretéritos". Como bem adverte Ricardo Marcelo Fonseca, 
ao estabelecer uma continuidade muitas vezes artificial e sem mediações entre o ontem e o hoje, pode resultar num instrumento banal para demonstrar a inevitabilidade do presente, colocando-o como ponto de chegada natural e conseqüente de um curso histórico homogêneo, resultando numa celebração acrítica do presente e de suas instituiçõos. $(2009$, p. 5)

O que se pretende sublinhar, pois, é que, diferentemente das posturas analíticas simplificadoras, a cultura jurídica está inserida em determinado tempo e, portanto, é constituída de historicidade (FONSECA, 2009). ${ }^{1}$ Essa historicidade, quando bem compreendida, rompe com a visão de que o direito segue um percurso linear e uma lógica ascensionista; muito ao contrário, a dinâmica histórica é, não raro, marcada por oscilações, contradições, descontinuidades, avanços e retrocessos.

Por isso o interesse aqui em compreender, ainda que de forma indiciária e exploratória, o perfil da cultura jurídica processual em formação no Brasil na segunda metade do século XIX.

Entenda-se por cultura jurídica (inclusive aquela ligada ao estudo do direito processual) o "conjunto de significados (standards doutrinários, padrões de interpretação, marcos de autoridade doutrinária nacionais e estrangeiras, influências e usos particulares de concepções filosóficas) que efetivamente circulavam na produção do direito e eram aceitos nesta época no Brasil" ou, ainda, pelo "conjunto de padrões e significados que circulavam e prevaleciam nas instituições jurídicas do Império (faculdades, institutos profissionais de advogados e magistrados, o foro, e, em alguns casos, no parlamento), e que atribuíam uma tipicidade ao direito brasileiro.” (FONSECA, 2006, p. 340)

Em outras palavras, "cultura jurídica é aquilo que circula, funciona e produz efeitos dentro de um determinado contexto histórico social." (FONSECA, 2006, p. 341)

Nessa perspectiva, como forma de elaborar um recorte espacial e temporal para delimitar o vasto campo de análise, o presente artigo centrará seus esforços na identificação da cultura jurídica relativa ao direito processual civil por meio da análise do pensamento e das obras dos principais lentes (denominação dos professores à época) da cadeira de direito processual civil nas duas faculdades de direito do Império (do Recife e de São Paulo). Procurar-se-á, ainda, compreender a projeção destes saberes no ambiente acadêmico e na cultura forense.

\section{A CULTURA JURÍDICA BRASILEIRA DA SEGUNDA METADE DO SÉCULO XIX: A CRIAÇÃO DAS FACULDADES DE DIREITO NO IMPÉRIO}


Seguindo o recorte temporal adotado por Ricardo M. Fonseca, cabe esclarecer que a escolha desta temporalidade para a compreensão da cultura jurídica nacional parte da hipótese de que "sobretudo a partir dos anos cinqüenta do século XIX que podem ser evidenciadas características mais claras e específicas no sentido de ser possível definir contornos de uma genuína cultura jurídica brasileira." (FONSECA, 2006, p. 347)

E isso se deu preponderantemente pela inexistência até então de cursos de Direito no Brasil e, ademais, pelo fato de que, naquele período, os bacharéis eram oriundos da Faculdade de Direito de Coimbra, o que conduzia à manutenção da tradição jurídica portuguesa já deveras arraigada no Brasil.

Na perspectiva de Wolkmer, a forte política centralizadora de Portugal, a par de impor sua tradição jurídica, sobrepujando o direito interno, tinha por objetivo consolidar um estatuto normativo estruturado para salvaguardar seus interesses, o que era reforçado por uma elite profissional que se articulava por práticas burocrático-patrimonialistas (2003, p. 73).

Para uma melhor compreensão, é importante ter em conta o contexto de oposições internas - manifestas ou latentes - vivenciado pelo Brasil na entrada da época liberal para constituir-se jurídica e politicamente. Convivia, de modo não harmônico, de um lado, a herança do antigo regime, marcado pelo estrutura social colonial centralizada, oligárquica e escravista, regulada pelas Ordenações Filipinas e pela legislação portuguesa colonial; de outro, o forte influxo dos ideais liberais, oriundos das revoluções estrangeiras (FONSECA, 2006, p. 345).

De fato, até a Independência todo aparato jurídico existente no Brasil era oriundo de Portugal, precipuamente pela vigência das Ordenações Filipinas. Há, portanto, um evidente nexo "de continuidade com a tradição jurídica herdada dos tempos colonial”, (FONSECA, 2006a, p. 65-66) cujo esforço para superação, ainda que de forma lenta e gradual, transparece com a criação de leis brasileiras e, especialmente, com a criação dos cursos jurídicos, em 1827, em São Paulo e outro em Recife.

É nesse contexto, com a criação das faculdades de direito do Império, que se começa a delinear a cultura jurídica brasileira, na medida em que se abre espaço para um desenvolvimento jurídico autônomo em relação a Portugal.

É bem verdade, porém, que, na primeira metade do século XIX, o ensino jurídico visava muitos mais servir às necessidades políticas do Estado e promover o preenchimento dos quadros políticos e burocráticos da administração pública do que a formação de juristas responsáveis pela constituição de uma cultura jurídica legitimamente nacional. É o que explica André Wander Bastos: 


\begin{abstract}
A criação e a formação dos cursos jurídicos no Brasil estava significativamente vinculada às exigências de consolidação do Estado Imperial e refletem as contradições e expectativas das elites brasileiras comprometidas com o processo de Independência. Emerso das contradições entre a elite imperial conservadora, vinculada ao aparato político colonizador e aos institutos jurídicos metropolitanos, e a elite nacional civil, adeptos aos movimentos liberais e constitucionais que sucederam à Revolução Americana e à Revolução Francesa, o incipiente Estado brasileiro, premido pela situação impositiva da Igreja, que controlava sua infraestrutura de funcionamento cartorial e eleitoral, buscou nos cursos jurídicos a solução possível para a formação de quadros políticos e administrativos que viabilizassem a independência nacional. (2000, p. 1)
\end{abstract}

Já na segunda metade do século XIX, porém, é que passou a surgir uma nova categoria de intelectuais, cuja atividade passa a ser inclinada ao estudo do direito à luz de critérios científicos e voltada ao ensino jurídico:

\begin{abstract}
A instalação dos cursos jurídicos fecundara uma geração nativa de juristas, e a profissão universitária estimularia o ciclo inaugural de autores brasileiros. Do norte e do sul viriam os bacharéis, plasmando uma nova cultura, substituindo àquela representada pela elite estabelecida desde a Colônia. (DUTRA, 1992, p. 49).
\end{abstract}

Cabe, portanto, perceber como esta "geração nativa de juristas" irá contribuir especificamente para formação de uma cultura jurídica processual.

\title{
3. DA PASSAGEM do PRAXisMo LuSitano PARA A FORMAÇÃo da DOUTRINA PROCESSUAL BRASILEIRA
}

Embora processualistas modernos encarem o desenvolvimento da cultura processual a partir de uma perspectiva exclusivamente dogmática, o que acaba por conduzir à conclusão de que o processo civil acompanha uma linha de progressiva evolução, olvidam-se dos aspectos históricos que subjazem a tais mudanças.

Ora, no Brasil do século XIX, avanços legislativos e científicos não foram impulsionados simplesmente pelo esforço acadêmico dos juristas, mas também pela influência e flutuações de fatores externos. Além do expressivo influxo do ideário liberal sobre a cultura jurídica brasileira neste período histórico ${ }^{2}$ e da instituição dos cursos jurídicos, a criação de uma legislação processual própria foi determinante, pois representou a imperativa necessidade de se regular uma das funções do Estado (o Poder Judiciário), assegurando, destarte, a soberania nacional (como reflexo da necessidade do rompimento do sistema processual lusitano).

Com isso se pretende afirmar que as criações legislativas a respeito do processo civil, e a cultura jurídica a respeito de tal saber, estão fortemente atreladas a um contexto histórico marcado pelo liberalismo, que "acabou constituindo-se na proposta de progresso e 
modernização superadora do colonialismo" e "na projeção das bases essenciais de organização do Estado e de integração da sociedade nacional.” (WOLKMER, 2003, p. 79)

É preciso advertir, porém, que o liberalismo brasileiro adquire contornos peculiares. Enquanto em países como Inglaterra, França e Estados Unidos o liberalismo representou a doutrina política libertadora que representou a ascensão da burguesia contra o absolutismo, no Brasil expressou a necessidade de reordenação do poder nacional, de eliminação dos vínculos coloniais e a manutenção da dominação das elites agrárias. Nas palavras de Emília Viotti da Costa:

No Brasil, as idéias liberais teriam um significado mais restrito, não se apoiariam
nas mesmas bases sociais, nem teriam exatamente a mesma função. (...) Os adeptos
das idéias liberais pertenciam às categorias rurais e sua clientela. As camadas
senhoriais empenhadas em conquistar e garantir a liberdade de comércio e a
autonomia administrativa e judiciária não estavam, no entanto, dispostas a renunciar
ao latifúndio ou à propriedade escrava. A escravidão constituiria o limite do
liberalismo no Brasil. (2007, p. 30$)$

Não se tratava, portanto, da batalha dos dominados para dissolver os privilégios da aristocracia e da realeza. Alude-se, neste particular, a uma contradição do liberalismo pátrio percebida pela "paradoxal conciliação "liberalismo-escravidão" (WOLKMER, 2003, p. 77), ou seja, o liberalismo funcionava como instrumento retórico para manter a dominação oligárquica e, concomitantemente, dar impulso ao desenvolvimento comercial. Nesse sentido é o ensinamento de Gizlene Neder:

Primeiramente, cabe ressaltar que o liberalismo se tornou uma ideologia necessária e
presente na conjuntura da emancipação política, fato que está intrinsecamente ligado
à criação dos cursos jurídicos no Brasil. Tanto em São Paulo, quando no Recife, os
postulados liberais foram invocados na luta contra o monopólio metropolitano na
qual engajara-se importantes segmentos ligados à grande propriedade agrária e
escravista. O liberalismo foi adotado, no entanto, com limitações e resguardados os
privilégios daqueles segmentos sociais e mantida a escravidão. A necessidade de
utilização do liberalismo produziu um duplo efeito: fundamentou a luta contra a
metrópole e delineou as linhas mestras da organização do Estado no Brasil (1995, p.
103).

Por isso a importância de que houvesse juristas e aparatos legislativos aptos a "sistematizar a ideologia político-jurídica do liberalismo" (integrando ideologicamente o Estado nacional projetado pelas elites) e constituir a "burocracia encarregada de operacionalizar esta ideologia” (RODRIGUES, 1993, p. 13).

Desse modo, além da concepção dos cursos jurídicos (com a consequente constituição de uma elite jurídica), outro fator de fomento da formação da cultura jurídica brasileira foi a elaboração de um expressivo arcabouço jurídico, composto notadamente pela 
Constituição de 1824, que se encontrava "imbuída de idéias e instituições marcadamente liberais", códigos e leis (WOLKMER, 2003, p. 84).

Para o propósito do presente estudo, interessa notar que o principal diploma processual da segunda metade do século XIX - o Regulamento 737 -, a partir do qual florescem os principais estudos do direito processual civil legitimamente nacionais, nasce na esteira do Código Comercial de 1850, marcado por forte conteúdo liberal e pela influência das necessidades do comércio da elite local. Embora influências liberais já se fizessem sentir, "o comércio era ainda incipiente em algumas práticas.” (LOPES, 2002, p. 292)

Conforme explica Wolkmer, "as necessidades imediatas, as atividades negociais e o desenvolvimento comercial fizeram com que a principiante burguesia latifundiária priorizasse a regulamentação da vida econômica sobre a vida civil." Deste modo, como "a ordenação do comércio e da produção da riqueza era mais imperiosa do que a proteção e garantia dos direitos civil, nada mais natural do que o Código Comercial preceder em 67 anos o Código Civil.” (2003, p. 88)

Porém, apenas a regulação das práticas comerciais pelas normas de direito material se revelava insuficiente para o propósito de outorgar segurança e agilidade ao trânsito econômico. Era preciso que, em caso de descumprimento do direito material, houvesse mecanismos processuais aptos a forçar o cumprimento das obrigações da maneira eficiente (o que se revelava difícil com o excessivo formalismo e arcaísmos das Ordenações). Para por em andamento a lei comercial foi indispensável "organizar os tribunais de comércio e neles dar nova ordem ao processo" (LOPES, 2002, p. 292).

Por isso mesmo, a legislação comercial foi acompanhada do Regulamento 737, que disciplinou o processo comercial até o advento da República (estendido posteriormente às causas cíveis), ditando as linhas gerais do processo de conhecimento, da execução e dos recursos.

O Regulamento 737 surge, assim, pela conveniência das elites nacionais de assegurar o natural funcionamento dos mecanismos de mercado e concomitantemente pela necessidade de se superar o processo formalista, complexo e moroso das Ordenações.

Com efeito, a legislação processual, "inspirada nas idéias liberais de que estavam imbuídos os homens que detinham o poder, destinava-se a transformar o processo civil em instrumento mais dúctil e menos complicados, despindo-o de atos e formalidades inúteis e de recursos excessivos, para possibilitar distribuição de justiça mais rápida e menos dispendiosa." (COSTA, 1970, p. 10) 
Por conseguinte, a necessidade de criação de uma legislação processual moderna e própria, ${ }^{3}$ somada à criação das faculdades de direito, abre espaço para os primeiros estudos na área do direito processual civil de cunho eminentemente nacional.

Como indicado preliminarmente, desde o período colonial até o ano de 1850, com a edição do referido Regulamento, o processo civil era regulado pelas Ordenações Filipinas. Neste longo período de vigência das normas portuguesas em matéria processual, não se contemplava ainda uma cultura jurídica brasileira dedicada à constituição de um pensamento relativo ao direito processual civil de raiz exclusivamente nacional.

Evidência maior dessa dependência reside no fato de que pouquíssimas foram as obras sobre processo civil editadas no Brasil antes da promulgação do Regulamento 737 de 1850 e de que obras jurídicas do direito processual civil de maior relevância eram, na verdade, adaptações nacionais de obras portuguesas (ROSA, 1970, p. 145-146). Teixeira de Freitas, por exemplo, adaptou para o direito nacional as "Primeiras Linhas", de Pereira e Sousa; J. J. Pereira da Silva Ramos adaptou a "Doutrina das ações", de José Homem Corrêa Telles; e Antonio Trigo de Loureiro anotou o "Manual de apelações e recursos", de Gouvêa Pinto.

Logo, na primeira metade do séc. XIX, o pensamento jurídico processual nacional não se encontrava dissociado do pensamento jurídico português, sendo-lhe fortemente tributário.

Por sua vez, merece destaque, como tentativa de inovação, aquela que é considerada uma das primeiras obras nacionais acerca do processo civil e que já carrega no seu âmago a expressão de uma vontade codificadora. Trata-se da "Revisão geral e codificação das leis civis e do processo no Brasil", do jurista e advogado, Francisco Ignácio de Carvalho Moreira (Barão de Penedo), publicada em 1846 (VENANCIO FILHO, 1982, p. 73). ${ }^{4}$

O livro tinha por objetivo a codificação da legislação civil e processual, sendo considerado um dos primeiros projetos de Código Civil. Muito embora não tenha obtido êxito na codificação das leis civis, Lobo da Costa esclarece que na referida obra "se encontram os germes de alguns princípios de natureza processual, que iriam frutificar no Regulamento n. 737, de cuja Comissão encarregada de elaborá-lo foi êle um dos principais membros, tendo sido o redator exclusivo do projeto." (COSTA, 1970, p. 27)

Carvalho Moreira atentava para o fato de que os juízes e advogados tinham a sua frente um quadro de leis muito extenso e totalmente desorganizado, que ia desde o direito romano, passando pelas ordenações e leis extravagantes portuguesas. Nesse contexto, era natural que as decisões judiciais fossem incoerentes e conflitantes. Como presidente do R. Fac. Dir. UFG, v. 38, n. 2, p. 13 - 40, jul. / dez. 2014 
Instituto dos Advogados Brasileiros, Carvalho Moreira pretendia combater este "monstruoso caos" em que se encontrava o foro "pelos defeitos e lacunas, obscuridade, confusão, e imensidade de nossas leis civis, e sobretudo das do processo." Conforme explica Eduardo Spiller Pena, a situação de insatisfação indicava "a ausência de um código de leis e do processo civil que padronizasse os usos e interpretações do direito no país". (PENA, 1996, p. $40)^{5}$

Da obra de Carvalho Moreira transparece um preliminar esforço de sistematizar o processo civil, uma latente predisposição à codificação das leis processuais, ${ }^{6}$ além da tentativa de romper com o praxismo que marcava os estudos lusitanos da prática forense (CRUZ E TUCCI, 2009, p. 178).

Por praxismo quer se significar aqui "a pré-história do direito processual civil", (MITIDIERO, 2009, p. 30) no qual a preocupação dos autores (os praxistas) residia em escrever sobre "a ordem do processo, ou a jurisprudencia formularia" a partir da experiência empírica. ${ }^{7}$ Conforme explica Dinamarco, no período praxista:

\begin{abstract}
os conhecimentos eram puramente empíricos, sem qualquer consciência de princípios, sem conceitos próprios e sem a definição de um método. O processo mesmo, como realidade da experiência perante os juízos e tribunais, era visto apenas como uma realidade física exterior e perceptível aos sentidos: confundiam-no com o mero procedimento quando o definiam como sucessão de atos, sem nada se dizerem sobre a relação jurídica que existe entre seus sujeitos (relação jurídica processual), nem sobre a conveniência política de deixar caminho aberto para a participação dos litigantes (contraditório). (2009, p. 260)
\end{abstract}

De fato, com a vigência do Regulamento 737, nota-se presente uma embrionária tendência dedicada à superação do legado transmitido pela experiência lusitana (WOLKMER, 2006, p. 424) e se faz crescente o surgimento no país de estudos doutrinários sobre o processo civil (COSTA, 1970, p. 26), a ponto de se afirmar que a maior contribuição do Regulamento residiu na constituição "da consciência processual brasileira”:

\begin{abstract}
A literatura processual, neste segundo período, é não só abundante, em razão dos muitos anos por que se estende, mas registra, também, o aparecimento de obra de qualidade superior. Um dos maiores méritos do Regulamento n. 737 foi o de propiciar a floração de estudos e trabalhos doutrinários sôbre o processo civil, com o que se iniciou a "formação de uma consciência processual brasileira". (COSTA, 1970, p. 33)
\end{abstract}

Evidentemente, não se pode deduzir que a partir de tal época tenha havido uma radical transformação metodológica, com a adoção universal de critérios científicos no estudo do direito processual, tampouco um rompimento com a herança ibérica. Ao contrário, em grande parte, a literatura do período se limitava a narrar a praxe forense, a reproduzir 
ensinamentos dos praxistas portugueses ou, como visto, a adaptar as obras lusitanas para o cenário nacional.

No entanto, nota-se neste período o surgimento de obras genuinamente nacionais que procuram estabelecer princípios gerais da ciência processual e promover sua sistematização, na esteira de uma postura intelectual de enaltecimento do método científico. É o que se verifica da obra de Pimenta Bueno, datada de 1858, jurista oriundo da primeira turma de bacharéis da Faculdade de Direito de São Paulo:

\begin{abstract}
A parte da legislação que estabelece as fórmas porque devem tratar-se as causas ou acções cives é a que denomina-se - Processo Civil. - Seu estudo é arido e fatigante, e sua theoria entre nós pouco cultivada. Nossos praxistas, na quasi totalidade, limitão-se a indicar os resumidos, e algumas vezes obscuros e incompletos preceitos das ordenações, os casos julgados, estylos ou opniões, algumas dellas controversas, sem desenvolver os princípios elementares desta parte da sciencia jurídica, e muito menos as razoes fundamentaes de suas diversas disposições. (...) em verdade o estudo do processo civil é digno de outra sorte e da mediação de illustradas intelligencais. Elle encerra graves questões e elevados princípios, que deve ser luminosamente contrastados.(...) Estudar as leis não é estudar sómente suas expressões, mas sim também sua theoria, seus princípios, sua razão, extensão, valor de seus preceitos e seu fim de publica utilidade. (BUENO, 1858, p. I-III)
\end{abstract}

Evidencia-se, pois, das palavras de Pimenta Bueno, concomitantemente o sentimento de ausência de uma "theoria" do processo civil, uma reação à metodologia dos praxistas e, em decorrência disso, a necessidade de que processo civil (enquanto parte da "sciencia jurídica") seja fundado em "sua theoria, seus princípios, sua razão" e fruto da "mediação de ilustradas intelligencias".

Portanto, demarca-se a inquietação quanto à superação do praxismo e a vagarosa passagem para a adoção de posturas cientificistas no tocante ao direito processual civil. (VENANCIO FILHO, 1982, p. 151)

Sem dúvida alguma, um fator impulsionador desta "consciência processual brasileira", com a marca da transição do praxismo para um cientificismo, foi a criação das faculdades de direito do império pela lei de 11 de agosto de 1827.

Calha observar que a referida lei continha a previsão de uma cadeira dedicada à disciplina "Teoria e Prática do Processo adotado pelas leis do Império" e, conforme explica Ricardo Marcelo Fonseca, estabelecia que os professores de cada disciplina deveriam adotar um compêndio a ser usado pelos alunos ou ainda escrever um. (2006, p. 351)

Se num primeiro momento as faculdades, ainda sob a forte influência portuguesa, adotaram obras de autores lusitanos (VAMPRÉ, 1977, p. 236), ${ }^{8}$ na segunda metade do século XIX é que se nota uma transformação significativa, já que os professores "das academias de direito serão majoritariamente brasileiros e com formação nas academias brasileiras, dentro de 
um contexto jurídico-político no qual o país já tinha trilhado caminhos próprios, diversos da sua antiga metrópole, no que diz respeito à cultura jurídica.” (FONSECA, 2006, p. 347)

É aí que passam a surgir os primeiros compêndios para ensino do direito processual civil criados pelos lentes brasileiros para fins de ensino da disciplina. Dentre tais compêndios destacam-se notadamente os dos lentes da Faculdade de Direito do Recife e de São Paulo, Francisco de Paula Batista e Joaquim Ignácio Ramalho (Barão de Ramalho), respectivamente, os quais serão brevemente examinados adiante com o propósito de se compreender as nuances da cultura jurídica da época respeitante ao direito processual civil.

A escolha destes lentes teve como fundamento duas premissas: primeiramente, partiu da identificação dos professores titulares da cadeira de direito processual civil nas faculdades de direito do Império; em segundo lugar, verificou-se se os referidos lentes produziram obras que foram utilizadas no ensino da disciplina e, assim, tiveram alguma influência e recepção pela comunidade jurídica.

A inegável relevância de tais lentes para a cultura jurídica processual é salientada por Alfredo Buzaid:

A doutrina processual brasileira surgiu também nessa época. Na Faculdade de Direito de Pernambuco, o ensino da cadeira de Processo fora confiado a Paula Batista e na Faculdade de direito de São Paulo ao Barão de Ramalho. Ambos foram mestres insignes, que regeram as suas cadeiras durante meio século, revelando, no cultivo do direito, o mais elevado espírito científico (1982, p. 51).

Cabe, portanto, compreender o papel destes lentes para a formação do acervo cultural do direito processual civil.

\section{FRANCISCO DE PAULA BATISTA}

Francisco Paula Batista formou-se na Faculdade de Direito do Recife em 1833, sendo que, em 1835, tornou-se lente substituto desta faculdade. Lecionou por 46 anos, jubilando-se em 1881, mesmo ano em que faleceu. Além de professor, foi político e deputado por nove legislaturas, tendo sido filiado ao Partido Liberal, embora inicialmente adepto do Partido Conservador (BEVILAQUA, 1977, p. 309).

Publicou dois livros, sendo ambos de grande importância para a compreensão da cultura jurídica brasileira do século XIX. O primeiro livro, de 1855, foi intitulado de "Compendio de theoria e prática do processo civil" e tinha por finalidade servir de roteiro para as aulas das Faculdades de Direito do Império do Brasil, sendo o compêndio empregado à época para a cadeira de "processo e prática forense" da faculdade de direito do Recife 
(BEVILAQUA, 1977, p. 103). A segunda edição, que, na verdade, correspondia a uma segunda obra, intitulou-se "Compêndio de Hermenêutica Jurídica", sendo que as edições posteriores vieram a reunir esses dois compêndios.

Sua obra de direito processual é avaliada por muitos como um marco em nossa literatura jurídica (DUTRA, 2004, p. 51-52) ${ }^{9}$ e precursora de modificações e posturas conceituais que apenas surgiriam anos à frente. Afirma-se, assim, que "antecipando-se aos demais quase meio século, reuniu, ordenou e sistematizou os elementos para revisão cientifica do direito processual civil brasileiro.” (BUZAID, 1982, p. 52)

Nas palavras de Clovis Bevilaqua, Paula Batista é "uma das grandes figuras da nossa jurisprudência" e seus dois livros "são dois primores de sínteses, onde se condensam, com firmeza e elegância, os conhecimentos jurídicos da época, em que foram escritos, e onde se encontram uma ciência exata e o tom de segurança dos doutrinadores de seu valor.”(1977, p. 308)

Importa perceber, nessa ordem de ideias, que a obra de Paula Batista é marcada pela incessante preocupação de estabelecer padrões científicos para o estudo do processo civil, o que se nota do prólogo da segunda edição de seu Compêndio:

Estou bem longe ainda de chegar ao fim dos meus desejos, os quaes, quero crer, só se poderia completar por meio de um tratado aprofundado sobre a theoria do Processo Civil; pois confesso que a vista da legislação, que temos, e dos velhos hábitos de considerar-se o processo, não como uma sciencia com princípios meios e fins, mas como formas matérias incapazes de melhoras e progresso, o bem difícil compendiar. (1857)

Essa mesma orientação é evidenciada no prólogo da sexta edição de sua obra:

Se os tratados aprofundados são úteis á sciencia, não menos util é resumir com clareza e precisão os principios, que regem uma materia. (...) Mas um livro pode ser elementar e conter, todavia, grande alcance scientico, o que muito vál, mormente no estudo do regime judiciário, cujas leis teem deixado em silencio até hoje grande somma de noções rudimentaes pelo motivo, sem duvida, de suppol-as adqueridas nas escolas de direito. A lei é certamente um preceito, e não uma doutrina; mas, em muitos casos, antes dos arestos deve existir o raciocínio e a doutrina. (1901)

Ricardo Marcelo Fonseca destaca na obra do processualista a presença do elogio ao método cientifico, atitude esta que passa a caracterizar a nova postura dos juristas a partir da segunda metade do século XIX. Para Fonseca

\begin{abstract}
as novas elaborações que vão tomando forma nos anos 60 e se desenvolvem de maneira mais clara a partir dos anos 70 do século XIX denotam que as referencias teóricas do jurista parecem ir se deslocando em direção à busca de um parâmetro científico racional, que vai se afastando, em forte tom polêmico, das teorias anteriores embebidas de uma interpretação teológica da lei natural. (2006, p. 356)
\end{abstract}

Com efeito, a própria aspiração de Paula Batista de estabelecer uma "theoria" para o processo civil faz denotar uma mutação de posicionamento diante deste saber, eis que, em 
oposição ao método praxista, apresenta clara "preocupação com a dogmática do Processo Civil, passando a ramo autônomo; até então, o processo civil era mera arte de instrumentalizar o direito material, práticas e praxes do foro, estando totalmente submetido ao direito material.” (ROSSONI, 2006, p. 532)

Incumbe compreender, neste passo, que o pensamento de Paula Batista desvenda certas características que marcaram a Escola do Recife, tal como a postura cientificista e a preocupação na formação de estudos com projeção nacional:

O intento do Grupo do Recife foi tratar o fenômeno jurídico a partir de uma pluralidade temática, reforçada por leituras naturalistas, biologistas, cientificistas, históricas e sociológicas, apoiando-se fortemente num somatório de tendências que resultavam basicamente no evolucionismo e no monismo, sem desconsiderar a crítica sistemática a certas formulações jusnaturalistas e espiritualistas (WOLKMER, 2003, p. 82).

Imprimindo solidez à argumentação, Antonio Paim explica que a Faculdade de Direito do Recife "estimula e desenvolve o interesse e o amor pela produção intelectual brasileira, herdada dos primeiros românticos mas despindo-a da feição ingênua de que se revestira. Esse trabalho agora assume a forma de inventário, pretende-se científico e duradouro.” (1999, p. 95)

De fato, além do forte influxo da ideologia liberal, a reflexão vivenciada na Escola do Recife permite notar a transposição do modelo do "jurista eloquente" - entendido como o jurista que se vale da palavra falada, da retórica, que cultua a literatura e os saberes das humanidades para uso em seu discurso - para o "jurista cientista", considerado aquele que valoriza a palavra escrita, "que vai de modo crescente constituindo revistas acadêmicas, o jurista que passa a valorizar, como fundamento legitimador de seu discurso, não mais as estratégias retóricas, mas a solidez dos argumentos científicos.” (FONSECA, 2006, p. 356)

Essa valorização dos argumentos científicos é perceptível em sua obra, eis que, longe de fundar-se em mero empirismo, seus estudos revelaram-se "fruto ordenado e sistemático de uma investigação original e rigorosamente cientifica.” (BUZAID, 1982, p. 87) Por isso mesmo, Paula Batista, revelando intenso espírito crítico, assinalava que o processo, à época, cingia-se "à arte de instrumentar, à tradição de usos e estilos, a ponto de num cartório se aprender melhor do que nas Academias.” (1855, p. VI)

No mesmo prólogo de seu "Compêndio", Paula Batista mostra nítida preocupação de que o ensino do direito se funde no "desenvolvimento filosófico da ciência com a aplicação de princípios gerais", reputando estéril o estudo consistente em decorar textos legais: 
O ensino do Direito, reduzido simplesmente aos textos de lei sem exame de suas razoes e de seu espírito, é um erro calamitoso e deplorável; por um lado afugenta os talentos, que querem aprender raciocinando e desenvolvendo a inteligência, sujeitando-os unicamente ao trabalho estéril e fastidioso de decorar; e a este respeito nunca me esquecerei das seguintes palavras dum notável jurisconsulto, professor duma das Academias de Direito de Paris: a letra da lei fica gravada na memória, quando o raciocínio lhe serve de buril; por outro lado encobre a insuficiência dos mestres que, por esse modo, ficando a salvo das soluções de todas as questões difíceis, não precisam entrar no desenvolvimento filosófico da ciência com a aplicação de princípios gerais, e conseguintemente nunca têm ocasião de patentear a extensão, mérito e valor de seu próprio espírito. (1855, p. V-VI)

Essa postura intelectual pode ser compreendida pela sua profunda percepção de problemas fundamentais do processo, muitos deles ainda sequer enfrentados pela própria doutrina processual europeia de seu tempo, tal como a questão da autonomia da ação, a natureza pública do processo e a coisa julgada.

À época, enquanto prevalecia o entendimento que o direito de ação era o direito subjetivo violado em reação (teoria imanentista ou civilista da ação) - quadro que apenas iria se modificar a partir da polêmica entre Windscheid e Muther e das obras de Adolf Wach (1886) e de Chiovenda (1903) -, Paula Batista intuitivamente já definira o direito de ação como "o direito de invocar a actoridade publica (juiz) e de obra regularmente perante ella para obter justiça.” (1901, p. 10)

Eis como Paula Batista decompõe a sua definição:

Às palavras «autoridade publica» alludem as leis de organisação judiciaria: as palavras «obrar regularmente» alludem as leis do processo, ou das formas; e todas estas leis compõem o regime judiciário, cuja instituição é de direito publico, e a noção da palavra «acção» o dá como já existindo. (1901, p. 10)

Há, portanto, a percepção de que o direito de postular tutela jurisdicional em face do Estado é algo autônomo em relação ao direito subjetivo que se discute em juízo, o que representa uma profunda evolução na dogmática processual (ROSSONI, 2006).

No entanto, passos adiante, Paula Batista aproxima-se de certas premissas da teoria imanentista da ação, aduzindo que "as acções são direitos em garantias de outros direitos preexistentes" e, assim, que "a cada direito deve corresponder uma acção" (1901, p. $10)$.

Aos olhos dos juristas de hoje, o que poderia aparentar uma incongruência em seu pensamento é na verdade expressão de um momento histórico particular, em que a busca por critérios científicos e pelo instituição de princípios explicativos deste saber encontrava-se ainda fortemente influenciada por uma tradição jurídica multissecular. Livrar-se dessas amarras jamais poderia ser reputada uma tarefa de simples implementação. 
No tocante à coisa julgada, e notadamente à discussão sobre qual parte da sentença é acobertada pelo efeito da imutabilidade, Liebman, em obra mais de um século posterior a de Paula Batista, ressalta a importância do pensamento do professor pernambucano na solução de enredado problema dogmático:

\begin{abstract}
A questão dos limites subjetivos da coisa julgada é uma das mais controvertidas no direito brasileiro. Resolveu-a, na verdade, há muito tempo, e de modo insuperável Paula Batista (...), quando afirmou que: a autoridade da coisa julgada é restrita à parte dispositiva do julgamento e aos pontos ai decididos e fielmente compreendidos aos seus motivos objetivos". Significa isso que os motivos da sentença não são objeto da coisa julgada, mas devem ser considerados para entender o verdadeiro e cabal alcance da decisão. (LIEBMAN, 2007, p. 61)
\end{abstract}

Outra temática enfrentada com apuro técnico por Paula Batista diz respeito aos sistemas de apreciação das provas, a partir da qual se denota uma perspectiva liberal do direito, sobretudo pela ênfase na necessidade de contenção de aberturas para o arbítrio do Estado-juiz.

Rejeitando o "puro systema da convicção livre e natural dos juizes", assim como o sistema das "provas positivas e obrigatórias", o processualista entende adequado um sistema intermediário, no qual o legislador deve estabelecer uma orientação sobre os meios do prova, a partir do qual o juiz terá liberdade de apreciação, mas a elas atrelado no momento da motivação do julgamento. Sua preocupação maior era que, com base no sistema da convicção livre, o poder jurisdicional recaísse em arbítrio, deixando a parte alheia aos motivos do julgamento:

É indispensável, que as sentenças estejão livres de toda a suspeita de parciaes e arbitrarias, e para que a confiança publica exista, é mister, que cada um se convença de que ellas são proferidas segundo as sabias instrucções da lei, e o juiz seja obrigado a dar contas de suas decisões. (...) as mesmas partes jamais poderião saber quaes as provas, que tocarão vivamente o juiz, e quaes as recusadas; e, por conseguinte, em caso de appellação não poderião bem defender os seus direitos. (1901, p. 175-179)

Paula Batista aponta para o risco de que, sem um critério de apreciação de provas seguro, diante dos "mesmos casos, e com as mesmas provas appareção julgamentos desiguaes, e contradictorios". Por isso, para ele "tudo deve estar sujeito ao dominio da sciencia e aos principios de responsabilidade.” (1901, p. 175-179)

Sua importância para a cultura processual, porém, não se limita a tais exemplos e não caberia aqui tratar de todos os aspectos dogmáticos por ele enfrentados. Sua obra, com efeito, considerada livro fundamental do direito processual brasileiro no século XIX, representa "a justificação teórica do maior monumento da processualística do Império, o regulamento 737.” (VENANCIO FILHO, 1977, p. 120) 
Lobo da Costa salienta que o "Compêndio" de Paula Batista é considerado a melhor obra interpretativa do Regulamento n. 737, cuja importância foi ter demonstrado a superioridade do sistema processual por ele instituído em comparação sobre o processo civil lusitano, além de ter evidenciado que esta diploma normativo - criado originariamente para as causas comerciais - era completamente apto para regular igualmente as causas cíveis. (COSTA, 1970, p. 51). Evidência maior disso é que o Regulamento - considerado “o verdadeiro código processual do Império" (VENANCIO FILHO, 1977, p. 65) - teve vigência até 1939, com a promulgação de um Código de Processo Civil, embora este represente, em grande medida, notadamente no processo de execução, mera reprodução do Regulamento de 1850 (COSTA, 1970, p. 101).

Ademais, dando conta de seu significativo papel, Bevilaqua afirma que a obra de Paula Batista pode ser comparada à de autores mais modernos, tal como João Monteiro (que, em 1883, substitui Joaquim Ignácio Ramalho na cátedra de Teoria e Prática do Processo Civil e Comercial na Faculdade de Direito de São Paulo). Embora o "Curso de Processo Civil" de Monteiro tenha sido fruto de um cenário histórico em que já havia se principiado na Europa expressivo movimento de renovação dos estudos de processo, isto não teve o efeito de reduzir a importância da obra de Paula Batista. Aliás, como bem registra Bevilaqua, o pensamento de Paula Batista é acolhido e referenciado com apreço por Monteiro:

\footnotetext{
O livro de João Monteiro reflete as conquistas do saber do seu tempo, em relação ao Direito judiciário, mas não desalojou o de Paula Batista do pedestal erguido pela admiração dos estudiosos. Aliás, João Monteiro dá, no seu Curso, reiteradas e eloquentes provas da estima, em que tem o velho tratadista pernambucano, a Teoria e Prática do processo civil. (1977, p. 311)
}

Além disso, em face de seu estilo exato e de simplicidade precisa, Paula Batista impôs um novo padrão de escrita jurídica. Com efeito, sua obra, não se restringido a ordenar a complexidade das normas processuais, foi disciplinadora do raciocínio processual (DUTRA, 2004, p. 51). Paula Batista, nas palavras de Buzaid, "plasmou a ciência processual brasileira, na obra diuturna do ensino acadêmico e nos seus livros científicos, onde a clareza de linguagem molda o rigor do pensamento.” (1982, p. 53)

\section{JOAQUIM IGNÁCIO RAMALHO}

Ao lado de Paula Batista, José Ignácio Ramalho (Barão de Ramalho) é considerado um dos grandes nomes do direito processual civil no século XIX. Tornou-se bacharel em direito pela Faculdade de Direito de São Paulo em 1834, “destacando-se como 
aluno brilhante, de méritos inegáveis" (VENANCIO FILHO, 1977, p. 124) e recebeu o grau de doutor em 1835. No ano seguinte foi nomeado lente substituto, tornando-se catedrático da cadeira de Processo e Prática Forense no ano 1854. Lecionou até 1883, quando então assumiu a direção da Academia de São Paulo. Além de professor, foi advogado e exerceu expressiva atividade política (VAMPRÉ, 1977, p. 185-192).

Entre 1856 e 1874, publicou cinco grandes livros: "Elementos de processo criminal, para uso das Faculdades de Direito do Império" (1856) "Practica Civil e Comercial" (1861), que era empregada para o ensino jurídico (VIDIGAL, 1954, p. 336), "Postillas de Pratica, precedidas de cinco Lições de Hermenêutica Jurídica" (1872),"Praxe Brasileira" (1868) e "Instituições Orfanológicas" (1874). Tais obras, segundo Spencer Vampré

\begin{abstract}
são verdadeiras consolidações do que mais seguramente haviam firmado os jurisconsultos nacionais e portugueses, sobre tudo portugueses porque português era o nosso Direito de então, como continuaria por quase meio século ainda o Direito e o Processo Civil. Há quem desdoure da obra de Ramalho; há quem, como Teixeira de Freitas, o averbe demasiado propenso ao antigo. Não somos deste número. Se lhe falta a intuição genial de Paula Batista, se o pensamento filosófico não lhe enfeixa nenhum princípio superior todas as regras parciais que investiga, ninguém lhe supera na exatidão das fontes, na compreensão da regra consolidada, na conciliação prudente entre o espírito e o passado e as novas necessidades do futuro. (1977a, p. 188)
\end{abstract}

De fato, uma análise das fontes que embasam as obras de Ramalho demonstra ainda forte apego aos ensinamentos dos processualistas portugueses, constantemente citados (especialmente Mello Freire e Pereira e Souza), assim como preponderante referência às Ordenações Filipinas ao tratar das normas processuais, embora já se faça presente a invocação de leis processuais brasileiras, notadamente o Regulamento 737 de 1850. Por isso a crítica de que era "propenso ao desusado" ou, quanto menos, "infenso à leitura de livros modernos". (VIDIGAL, 1954, p. 335-336)

Ademais, o lente “pendia para o direito positivo" (VAMPRÉ, 1977, p. 188), o que se nota pela preponderante referência ao texto legal como fundamentação de seu pensamento.

Certas concepções ideológicas, especialmente a desconfiança em relação ao arbítrio judicial e a ênfase à formalidade processual, orientam seu pensamento. Em vários trechos Ramalho enfatiza, destarte, que o

uso das formulas é uma necessidade na jurisprudencia, porque, comquanto o juiz
seja um sacerdote da lei, a quem incumbe velar na observancia della, (...) o
exercicio desse direito no magistrado não deve ser arbitrario, deve ser regulado por
uma lei: portanto para que se evite o abuso da parte do executor da lei, é necessario
que ella previamente estabeleça o modo e formulas de se a executar. (1872, p. $27-$
29)

Se, na visão do lente da Academia de São Paulo, a função do processo era a descoberta da verdade, tal descoberta se dava mediante o respeito à forma. É o que se vê sua R. Fac. Dir. UFG, v. 38, n. 2, p. 13 - 72, jul. / dez. 2014 
definição de processo como a "fórma estabelecida pelas leis para se tratarem as causas em juizo" (1861, p. 29) e da equiparação da sentença acobertada pelos efeitos da coisa julgada à verdade. (1861, p. 149)

Como não poderia ser diferente dentro deste contexto histórico, Ramalho é tributário de uma concepção liberal do direito, na qual não era reconhecido ao juiz o papel de construção do fenômeno jurídico, cabendo a ele captar a "verdade" dos fatos, que se supunha objetivamente identificável, e ser a boca que pronuncia as palavras da lei.

Ademais, diferentemente da aguçada reflexão processual encontrada em Paula Batista, o que realmente marca a obra de Ramalho é o seu sentido prático, ${ }^{10}$ que se nota a partir do empirismo das observações e da valorização do cotidiano forense como fonte do direito:

\begin{abstract}
Não foi nossa intenção escrever para os jurisconsultos e práticos do foro, destes só queremos e a lição e conselho, nosso pensamento é mais modesto, e sinceramente o revelamos. (...) De que serviria conhecermos a extenção, e medida de nossos direitos, se ignorássemos a acção que os defende, o braço que os protege, e as regras que devem presidir à estas lutas forenses que surgem cada dia do conflicto dos interesses particulares? Determinar pois os princípios da competência, segundo a natureza de cada causa; prescrever o modo de instaurar o processo, e a maneira de defender-se; expor as leis da discussão, as regras da prova; determinar como se dão as sentenças, se reformão, e se executão; eis as difernetes questões geraes de que se ocupa o direito formal. (1861, p. V-VIII)
\end{abstract}

Este sentido prático é salientado por Vidigal quanto aduz ao estilo "conciso e lapidar” da obra de Ramalho, na qual “é sempre fácil encontrar um conceito” (1954, p. 337).

Denota-se, ainda, em sua postura o comprometimento com a atividade docente, já que, com suas obras, visava "facilitar à mocidade estudiosa os meios de se habituarem para um dia servirem melhor ao paiz" (VAMPRÉ, 1977, p. 190-192). Porém, sua obra suplantou os meros propósitos didáticos e assumiu projeção perante operadores do foro e doutrinadores, tendo relevância "no curso diário da vida forense" (DUTRA, 1992, p. 55-56).

Sua contribuição, conforme explica Dutra, foi ser realista "quando mostrava o estorvo de uma legislação caótica, confusa de leis abrogadas e em vigor, com a de seu tempo", além de sistematizar as obras portuguesas, nos esforço de "conciliação prudente entre o espírito e o passado e as novas necessidades do futuro" (1992, p. 51-56).

\title{
6. A RECEPÇÃO DO PENSAMENTO PROCESSUAL NOS JULGADOS
}

Ultrapassada esta brevíssima análise, resta agora compreender se o pensamento dos lentes e seus compêndios para o ensino da disciplina podem indicar a formação de cultura jurídica relativa ao direito processual na segunda metade do século XIX. Cabe examinar, em R. Fac. Dir. UFG, v. 38, n. 2, p. 13 - 40, jul. / dez. 2014

ISSN 0101-7187 
outras palavras, se tais saberes circularam e produziram efeitos dentro de um contexto histórico e social.

Primeiramente, parece certo que os compêndios dos referidos lentes tiveram reflexo nos subsequentes estudos de direito processual civil. Como demonstrado em passagens anteriores, o pensamento de Paula Batista, por exemplo, foi objeto de reflexão e enaltecimento por Liebman em obra de 1945 sobre a coisa julgada. Ademais, em seu escrito sobre os "Istituti di diritto comune nel processo civile brasiliano", Liebman faz referência tanto a obra de Paula Batista quanto a de Ramalho quando trata de uma temática de relevo para a dogmática processual: a refomatio in pejus na apelação, admitida como possível pelos lentes brasileiros e respalda pelas Ordenações Filipinas, mas que não mais encontrava acolhida na doutrina dominante ao tempo do estudo do professor italiano (LIEBMAN, 1962 p. 508).

João Pereira Monteiro, que passa a substituir Ramalho na cadeira de Teoria e Prática do Processo Civil e Comercial na Faculdade de Direito de São Paulo, em estudo publicado no primeiro volume da Revista da Faculdade, também refere-se com frequência ao compêndio de Paula Batista em estudo no qual aquele procura estabelecer uma "teoria geral das ações" (MONTEIRO, 1893, p. 7-31).

A projeção assumida pelo pensamento de tais lentes pode ainda ser notada pelo exame das obras de Pontes de Miranda, que, em seus "Comentários ao Código de Processo Civil” de 1939 (legislação processual que sucede ao Regulamente 737 de 1850), faz devotadas referências à obra dos processualistas. Os "Comentários" abrangem 23 citações da obra Paula Batista e 26 de Ramalho (PONTES DE MIRANDA, 1947).

Nada obstante essa repercussão no âmbito doutrinário, a fim de se confirmar, ainda que indiciariamente, a hipótese da formação, a partir da segunda metade do século XIX, daquilo que Lobo da Costa denominou "consciência processual brasileira", o presente estudo toma como metodologia investigativa - de caráter meramente exploratório - a análise de julgados publicados nos primeiros fascículos da Revista "O Direito", que abrangem o ano de 1873, assim como os primeiros fascículos da "Revista de Direito Civil, Commercial e Criminal", referente ao ano de $1906 .^{11}$

Embora seja um âmbito investigativo temporalmente restrito, levando-se em conta a escassez de fontes de pesquisa jurisprudencial no período, é possível reunir indícios de que os saberes produzidos na academia passaram a ter gradativa projeção nos julgados.

Vale ressaltar que a cultura jurídica forense à época apresenta grandes diferenças da atual, a começar pelos acórdãos, que "tendem a ser curtos, breves, e os arrazoados R. Fac. Dir. UFG, v. 38, n. 2, p. 13 - 72, jul. / dez. 2014 ISSN 0101-7187 
forenses, bem como as próprias decisões, não se alongam em citações. Cita-se a lei, argumenta-se em torno da lei, mas também um pouco de doutrina" (LOPES, 2002, p. 333).

Com efeito, num universo de 54 julgados tratando de matéria processual presentes nos fascículos de 1873 da Revista "O Direito", 21 deles não contavam com qualquer referência doutrinária. Nos 33 restantes, colhe-se 6 referências à obra de Paula Batista e 5 à de Ramalho. Entre as alusões a processualistas brasileiros, menções ao livro de Pimenta Bueno (2) e de Souza Pinto (2). ${ }^{12}$

Quanto às principais referências a autores portugueses, há significativa menção às obras de Pereira e Sousa (23), além de Correia Telles (3) e de Lobão (8).

Dos 54 julgados tratando de matéria processual, 19 faziam expressa referência às Ordenações Filipinas, 21 ao Regulamento n. 737 de 1850 e 9 deles a legislações processuais brasileiras esparsas. ${ }^{13}$

Se analisado um período posterior, constata-se uma maior projeção do pensamento dos referidos autores brasileiros. De 65 julgados tratando de matéria processual presentes na "Revista de Direito Civil, Commercial e Criminal", de 1906, 20 deles não contavam com qualquer referência doutrinária. Nos 45 restantes, colhe-se 14 referências à obra de Paula Batista e 7 à obra de Ramalho. Destacam-se, ainda, entre as alusões a processualistas brasileiros, as menções a livros do Conselheiro Ribas (13), de João Monteiro (7), de Pimenta Bueno (2) e de Souza Pinto (3).

No tocantes aos autores portugueses, novamente nota-se recorrente menção às obras de Correia Telles (9), de Pereira e Sousa (17) e de Lobão (5). Dos 65 julgados tratando de matéria processual, 26 faziam expressa referência às Ordenações Filipinas, 37 ao Regulamento n. 737 de 1850 e 27 deles a legislações processuais brasileiras esparsas.

A partir destes dados, é possível notar que a cultura forense ainda apresentava-se sob significativo domínio dos autores portugueses, ${ }^{14}$ embora despontem gradativamente referências aos processualistas brasileiros. Da mesma forma, com a criação de uma legislação processual própria, as Ordenações passam a ter seu âmbito de incidência mitigado.

Para ilustrar este cenário, vale a referência a um caso julgado em 1873 e presente no primeiro volume da Revista "O Direito" (1873, p. 416-420), em que a parte recorrente e o magistrado apresentam seus argumentos - sobre a técnica processual dos efeitos recursais contrastando a obra de Paula Batista com a do português Pereira e Souza, além de ter como pano de fundo a incidência do Regulamento 737 e das Ordenações. Eis a argumentação da parte recorrente: 
Logo, desde que o processo seguido foi summario, não podia a apellação ter outro effeito além do devolutivo. Esta é a opnião seguida por todos os tratadistas, com exceção unica de Paula Batista, que no $§ 208$ da Theoria do processo sustenta dever haver o effeito suspensivo nos embargos à execução, oppostos pelo executado, ou por terceiro, sendo julgados provados.

Funda-se, porém, Paula Batista, no art. 652 do Regulamento n. 737 de 25 de Novembro de 1850; esta legislação é, porém, toda privativa do fôro commercial, nenhuma applicação tendo no fôro civil.

Quanto aos embargos de terceiros, é incontestavel que a apellação da sentença que os recebe tem o effeito suspensivo; mas isto porque também estes embargos são processados ordinariamente (Pereira e Souza, not. 897); acrescentando Pereira e Souza: porque, ficando suspensa a execução deve continuar a suspensão até finalisar seu conhecimento. Quanto, porém aos embargos do executado, não se dá o mesmo, porque tem procedimento summario, ensinando Pereira e Souza, no n. 3 da not. 889, que não se dá a apelação suspensiva da sentença proferida sobre os embargos do executado, excepto quando o juiz excede o modo da execução.

A Ord. liv. $3^{\circ}$, tit. $76 \S 2^{\circ}$, diz que quatro são os modos, pelos quaes póde o juiz exceder a execução; em nenhum deles está compreendida a sentença. Logo a appellação sópoderia ser recebida no efeito devolutivo.

Pelo que sobreveio a decisão do magistrado Joaquim Francisco de Faria, oriundo da Faculdade de Direito de São Paulo e que depois tornar-se-ia ministro do Supremo Tribunal Federal:

\footnotetext{
Não é exacta, em toda sua extensão, a these posta pela agravante, de quem tem sempre o efeito devolutivo, somente, a apelação nas causas summarias.

O proprio Pereira e Souza, Prim. Lin. sobre o processo civil, not. 633, não diz desse modo tão amplo como quer a agravante; e o Dr. Paula Batista, Theoria e Pratica do Processo Civil, $3^{\mathrm{a}}$ edic., not, $1^{\mathrm{a}}$ do $\S 227$, brilhantemente combate aquella these, citando exemplos frisantes e irrecusáveis de causas summarias, nas quaes a apelação tem ambos os efeitos.

Segundo é a sentença á favor ou contra o arrestante; e neste sentido tenho lido constantes decisões do Tribunal da Relação.

Pereira e Souza, aliás tão notável, não encera a questão por todos os seus lados, quando na not. 889 diz: «que não se dá apelação suspensiva da sentença proferida sobre embargos do executado»; parecendo-me que, pelas razões aduzidas pelo Dr. Paula Batista, deveria, como faz este, distinguir as hypotheses de ter sido a sentença á favor, ou contra o executado.
}

É perceptível, portanto, a partir deste exemplo e do referencial jurisprudencial examinado, que o pensamento engendrado pelos referidos lentes transitava nos ambientes de produção e interpretação do direito. Por sua vez, a cultura jurídica processual brasileira, ainda numa fase embrionária, encontrava-se em um período de gradual transição entre a arraigada tradição portuguesa (doutrinária e legislativa) e a nascença de estudos jurídicos genuinamente nacionais concernentes ao processo civil.

\section{CONCLUSÕES}


Tal como qualquer forma de saber, o direito processual civil está inserido em seu tempo, sendo, portanto, composto de historicidade. A ciência processual civil é um princípio de organização de um saber historicamente variável, seja em relação à função que se lhe atribui, seja com respeito às condicionantes culturais, sociais, políticas e ideológicas em que está embutida.

Por isso a ponderação de que o direito processual é o campo do saber jurídico mais severamente comprometido com a história, já que não se atém a formular regras abstratas, tal como o direito material, mas visa interferir nos conflitos concretos (SILVA, 1997). Ora, pretender estudar o direito processual de forma isolada da realidade social, significa camuflar o fato de que as normas processuais estão atreladas e submetidas a um determinado sistema de domínio que refletem e sancionam relações historicamente determinadas entre as diversas classes sociais e entre os diversos setores privilegiados dentro das classes dominantes (CHIARLONI, 1975).

Com efeito, a compreensão da cultura processual relativa ao direito processual civil brasileiro na segunda metade do século XIX exige sensibilidade em relação às singularidades de um momento histórico de transição e tensão, de ruptura e continuidade; no qual a herança jurídica europeia foi submetida a um progressivo procedimento de amoldamento às particularidades e contradições do Estado que aspirava pela autonomia.

De fato, trata-se de um período histórico em que interagem, de forma alternada, ruptura (expressa na emancipação política, na elaboração de uma legislação nacional e na criação das faculdades de Direito) e continuidade (pela manutenção da vigência das Ordenações e pelo ainda forte influxo da tradição jurídica portuguesa).

Logo, a cultura processual brasileira, percebida pelas obras dos lentes, reflete as vicissitudes desse contexto histórico. Com efeito, o esforço de modernização do direito, a busca por critérios científicos e o estabelecimento de princípios explicativos para o saber jurídico, convivia - por vezes de forma contraditória - com a forte influência da herança jurídica portuguesa e, por conseguinte, com os arcaísmos do processo medieval.

Os compêndios de Paula Batista e do Barão de Ramalho retratam, portanto, esse período de passagem do processo civil ainda regulado pelas Ordenações Filipinas e compreendido à luz das obras dos praxistas portugueses para um saber que aspira por se edificar em alicerces científicos e desembaraçar-se das amarras do passado. O próprio Regulamento n. 737 de 1850, considerado o Código Processual do Império, é uma evidência disso: ao mesmo tempo em que criou uma "consciência processual brasileira" preservou-se muito da cultura antiga. 
Manifesta-se, por conseguinte, nos estudos sobre o direito processual da época, a preocupação em superar o processo formalista, complexo e lento das Ordenações. Não se ambicionava, portanto, democratizar o acesso à justiça - mesmo porque o desenvolvimento do direito processual civil neste período encontrava-se intimamente ligado aos interesses do Estado e das classes dominantes, assim como à ideologia liberal.

Em outras palavras, os desenvolvimentos experimentados por este saber transcorreram de fatores diversos. Na segunda metade do século XIX, o debate teórico evidenciava o anseio de superar o jusnaturalismo, cuja solução foi encontrada na adoção de uma postura cientificista. Daí porque se vê no discurso dos processualistas da época a crítica aos "velhos hábitos", a afirmação da necessidade de se estabelecer princípios para uma "theoria entre nós pouco cultivada" e o constante enaltecer da "sciencia". ${ }^{15}$

Outro fator explicativo residiu na necessidade de se regular uma das funções do Estado, reafirmando a soberania nacional (e a ruptura dos laços com Portugal), e de se assegurar o adequado funcionamento do trânsito econômico decorrente de negócios jurídicos e operações comerciais.

Não é por casualidade que as temáticas discutidas nos tribunais dizem respeito aos interesses das elites, tais como operações de compra e venda, descumprimento de contratos comerciais, negócios societários, falências, circulação de mercadorias e títulos e ações de liberdade de escravos.

De qualquer sorte, o saber engendrado na academia pelas obras de Paula Batista e de Ramalho transitou em diferentes temporalidades, em distintos contextos acadêmicos e refletiu-se na vida forense, contribuindo para a gênese de uma cultura jurídica processual brasileira. Ilustrando tal ordem de ideias, assim explana Clovis Bevilaqua:

Um, Ramalho, tira solidez, da sua construção jurídica, da análise cuidadosa das fontes, dirigida ao critério jurídico. Noutro, em Paula Batista, as sínteses luminosas sistematizam os elementos dispersos e obscuros, dando ordem a preceitos desconexos, e preparando bases para a reforma do processo. Ambos, são igualmente, eruditos, mas em Ramalho, a erudição, é instrumento para verificação das normas, e, em Paula Batista, é escada para o cimo, de onde olha e domina, os fenômenos estudados (1977, p. 311).

Cabe, por fim, ter em mente que as concepções filosóficas, ideológicas, políticas relacionam-se e moldam determinada cultura jurídica, do mesmo modo que transpassam o direito e a sua concreta regulamentação, atribuindo-lhe historicidade e imprimindo-lhe significados e dinâmicas que o mero texto da lei não poderia revelar. Por isso mesmo, a leitura do passado deve ser contextualizada, confrontada e problematizada. 
É justamente aí que a história do direito manifesta suas mais relevantes funções: de um lado, a de revelar que o direito deve ser compreendido em sua autêntica dinâmica histórica, que segue um percurso marcado por oscilações, contradições, descontinuidades, avanços e retrocessos; de outro, a de desfazer "convicções acríticas, relativizando certezas consideradas absolutas, insinuando dúvidas sobre lugares comuns recebidos sem uma adequada confirmação cultural” (GROSSI, 2007, p. 13).

\section{BIBLIOGRAFIA}

ALVIM NETTO, José Manoel de Arruda. Revisão dogmática do direito processual civil. Alguns aspectos decorrentes dessa reelaboração. Revista do Instituto de Pesquisas e Estudos, n. 3, 1967.

BATISTA, Francisco de Paula. Compêndio de theoria e prática do Processo Civil comparado com o Commercial e de hermenêutica jurídica para uso das faculdades de direito do Imperio. 2 ed. Rio de Janeiro: Pinto e Waldemar, 1857.

Compêndio de theoria e prática do Processo Civil comparado com o Commercial e de hermenêutica jurídica para uso das faculdades de direito do Imperio. 4 ed. Rio de Janeiro: H. Garnier, 1890.

Compêndio de theoria e prática do Processo Civil comparado com o Commercial e de hermenêutica jurídica para uso das faculdades de direito do Imperio. 6 ed. Rio de Janeiro: H. Garnier, 1901.

BEVILAQUA, Clovis. Histórica da Faculdade de Direito do Recife. 2. ed. Brasília: Instituto Nacional do Livro, 1977.

BORGES, Marcos Afonso. História dos cursos jurídicos, suas tradições socioculturais para o país. Revista da Faculdade de Direito da Universidade Federal de Goiás, v. 13, n. 1, 1990.

BUENO, José Antonio Pimenta. Apontamentos sobre as formalidades no processo civil. 2. ed. Rio de Janeiro: Typographia Nacional, 1858.

BUZAID, Alfredo. Grandes processualistas. São Paulo: Saraiva, 1982.

CHIARLONI, Sergio. Introduzione allo studio del diritto processuale civile. Torino: G. Giappichelli, 1975.

CHIOVENDA, Giuseppe. Saggi di diritto processuale civile. Bologna: Zanichelli, 1904.

COSTA, Emilía Viotti da. Da Monarquia à República: momentos decisivos. 8 ed. São Paulo: Fundação Editora UNESP, 2007.

COSTA, Moacir Lobo da. Breve notícia histórica do direito processual civil brasileiro e sua literatura. São Paulo: RT-Edusp, 1970. 
CRUZ E TUCCI, José Rogério; AZEVEDO, Luiz Carlos de. Lições de história do processo civil lusitano. São Paulo: RT, 2009.

DINAMARCO, Candido Rangel. Instituições de direito processual civil. São Paulo: Malheiros, 2009, t. I.

DUTRA, Pedro. A literatura jurídica no Império. Rio de Janeiro: Topbooks, 1992.

DUTRA, Pedro. A literatura jurídica no Império. 2 ed. Rio de Janeiro: Padma, 2004.

FAORO, Raymundo. Existe um pensamento político brasileiro? Estudos avançados, v.1, n.1, 1987.

FONSECA, Ricardo Marcelo. A cultura jurídica brasileira e a questão da codificação civil no século XIX. Revista da Faculdade de Direito da Universidade Federal do Paraná, v. 44, 2006a.

Dal diritto coloniale alla codificazione: appunti sulla cultura giuridica brasiliana tra Settecento e Novecento. Quaderni Fiorentini per la Storia del Pensiero Giuridico Moderno, n. 33/34, t. II, 2004/2005.

. Introdução teórica à histórica do direito. Curitiba: Juruá, 2009.

Os juristas e a cultura jurídica brasileira na segunda metade do século XIX. Quaderni Fiorentini per la Storia del Pensiero Giuridico Moderno, n. 35, t. I, 2006.

. Vias da modernização jurídica brasileira: A cultura jurídica e os perfis dos juristas brasileiros do século XIX. Revista Brasileira de Estudos Jurídicos, v. 98, 2008.

GROSSI, Paolo. Mitologias jurídicas da modernidade. 2. ed. Florianópolis: Fundação Boiteux, 2007.

HESPANHA, António Manoel. Cultura jurídica européia: síntese de um milênio. Florianópolis: Fundação Boiteux, 2005.

2006.

O direito dos letrados no império português. Florianópolis: Fundação Boiteux,

LIEBMAN, Enrico Tullio. Eficácia e autoridade da sentença e outros escritos sobre a coisa julgada. 4. ed. São Paulo: Forense, 2007.

Problemi del processo civile. Napoli: Morano Editore, 1962.

LOPES, José Reinaldo de Lima. O direito na história - Lições introdutórias. 2.ed. São Paulo: Max Limonad, 2002.

LOPES, José Reinaldo de Lima; QUEIROZ, Rafael Mafei Rabelo; ACCA, Thiago dos Santos. Curso de História do Direito. São Paulo: Método, 2006. 
MITIDIERO, Daniel. Colaboração no processo civil: pressupostos sociais, lógicos e éticos. São Paulo: RT, 2009.

MONTEIRO, João Pereira. Programa do Curso de Processo Civil ou Apontamentos para as lições da 3. ${ }^{\mathrm{a}}$ cadeira do $4 .^{\mathrm{a}}$ anno da Faculdade de Direito de S. Paulo. 2. ed. São Paulo: Duprat \& Comp., 1901.

. Theoria do Processo Civil e Comercial. Revista da Faculdade de Direito de São Paulo, v. 1, 1893.

38 MOREIRA, Francisco Ignácio de Carvalho. Revisão geral e codificação das leis civis e do processo no Brasil, 1846.

NASCIMENTO, Walter Vieira do. Lições de história do direito. 14. ed. Rio de Janeiro, Forense, 2002.

NEDER, Gizlene. Discurso jurídico e ordem burguesa no Brasil. Porto Alegre: Sérgio A. Fabris Editor, 1995.

- Coimbra e os juristas brasileiros. Disponível em: http://www.estig.ipbeja.pt/ ac_direito/neder_coimbra.pdf. Acesso em 15 ago. 2013

OLIVEIRA, João Gualberto. 50 Anos do Instituto dos Advogados de São Paulo. São Paulo: IASP, 1966.

PAIM, Antonio. A Escola do Recife: estudos complementares à história das idéias filosóficas no Brasil. 3. ed. Londrina : EDUEL, 1999

PAULA, Jônatas Luiz Moreira de. História do direito processual civil brasileiro - Das origens lusas à escola crítica do processo. Barueri: Manole, 2002.

PENA, Eduardo Spiller. Um romanista entre a escravidão e a liberdade. Afro-Ásia, n. 18, 1996.

PONTES DE MIRANDA, Francisco Cavalcanti. Comentários ao Código de Processo Civil. Rio de Janeiro: Forense, 1947, vol. I a VI.

RAMALHO, João Ignácio. Postillas de pratica. 2. ed. São Paulo: Typographia Americana, 1872.

Practica civil e comercial. São Paulo: Typographia Imparcial, 1861.

RIBAS, Antonio Joaquim. Consolidação das leis do processo civil. Rio de Janeiro: Typhografia Carioca, 1879.

RODRIGUES, Horácio Wanderlei. Ensino jurídico e direito alternativo. São Paulo: Editora Acadêmica, 1993.

ROSA, Eliézer. Leituras de processo civil (generalidades sôbre doutrina processual civil). Rio de Janeiro: Guanabara, 1970. 
SILVA, Ovídio Araújo Baptista da. Jurisdição e execução na tradição romano-canônica. 2. ed.. São Paulo: RT, 1997.

Processo e ideologia: o paradigma racionalista. 2. ed. São Paulo: Saraiva, 2006.

TARELLO, Giovanni. Dottrine del processo civile: Studi storici sulla formazione del diritto processuale civile. Bologna: Il Mulino, 1989.

VAMPRÉ, Spencer. Memórias para a História da Academia de São Paulo. 2. ed. Brasília: Instituto Nacional do Livro, 1977, v. 1.

VENANCIO FILHO, Alberto. Das arcadas ao bacharelismo. 2. ed. São Paulo: Perspectiva, 1982.

VIDIGAL, Luis Eulálio de Bueno. Os mestres de Direito Judiciário Civil na Faculdade de Direito de São Paulo. Revista da Faculdade de Direito, v. 49, 1954.

WOLKMER, Antônio Carlos. Fundamentos de história do direito. 3. ed. Belo Horizonte: Del Rey, 2006.

História do direito no Brasil. 3. ed. Rio de Janeiro: Forense, 2003.

\footnotetext{
NOTAS

${ }^{1}$ Conforme explica Fonseca, "todas as disciplinas - de modo explícito ou não - têm seus estatutos e credenciais 'científicos' vinculados com as vicissitudes que são eminentemente históricas e, portanto, ligadas a uma provisoriedade e uma 'mundanidade'. Não há nenhuma razão supra-histórica que, de um modo metafísico, imponha um determinado ramo do saber como o 'privilegiado' em um espaço e em um tempo. Nenhum saber se impõe por si mesmo, pois, afinal, os saberes também fazem parte do jogo de forças que compõe o mundo histórico em que vivemos.” (2009, p. 22)

2 "Tanto em São Paulo, quando no Recife, os postulados liberais foram invocados na luta contra o monopólio metropolitano na qual engajara-se importantes segmentos ligados à grande propriedade agrária e escravista. O liberalismo foi adotado, no entanto, com limitações e resguardados os privilégios daqueles segmentos sociais e mantida a escravidão. A necessidade de utilização do liberalismo produziu um duplo efeito: fundamentou a luta contra a metrópole e delineou as linhas mestras da organização do Estado no Brasil.” (NEDER, Coimbra e os juristas brasileiros, p. 11)

${ }^{3}$ Dentre as vantagens do Regulamento enumera-se: "distribuição sistemática da matéria, a concisão e precisão da linguagem técnica, ausência de antinomias e geminações, simplificações dos atos processuais, redução dos prazos e melhor organização dos recursos" (NASCIMENTO, 2002, p. 221).

${ }^{4}$ Carvalho Moreira, originário de Alagoas, matriculou-se na Faculdade de Direito do Recife em 1834, porém formou-se em São Paulo em 1839, além de advogado eminente, "fundou, com Teixeira de Freitas, Caetano Alberto, Sousa Pinto, França e Leite e outros, o Instituto da Ordem dos Advogados Brasileiros" (BEVILAQUA, 1977, p. 35, nota 65)

${ }^{5}$ Nas palavras de Carvalho Moreira: "E que de terríveis conseqüências para a estabilidade a justiça, e segurança dos direitos civis, para a paz e felicidade das famílias, efetividade dos contratos, e manutenção da propriedade, não devem constantemente resultar deu uma tal confusão de leis, de tão monstruoso caos?” (PENA, 1996, p. 40).

${ }^{6}$ Este esforço codificador continuará presente e resultará na Consolidação das Leis do Processo, do Conselheiro Antônio Joaquim Ribas, que passa a ter força de lei em virtude da resolução imperial de 28 de dezembro de 1876 . Já no período republicano, houve a autorização para que os Estados criassem códigos processuais próprios. Posteriormente, no Estado Novo, com a atribuição de competência exclusiva de competência da União para legislar sobre matéria processual, surge o Código de Processo Civil de 1939.

${ }^{7}$ Exemplo retirado do periódico português "O Instituto", do ano de 1861, que, ao expor sobre praxistas destacados, se refere a um deles (Antonio Vanguerve Cabral, autor de Practica Judicial, de 1712), como "um mero practico sem fundo de direito" e que o mérito de sua obra "é trazer regularmente as formulas de todos os autos judiciaes." (Prelecções de direito patrio, que dava Ricardo Raymundo Nogueira, no anno de 1795 a 1796. O Instituto: Jornal Scientifico e Litterario. Coimbra: Imprensa da Universidade, 1861, v. XI, p. 241-242).

${ }^{8}$ Assim explica Spencer Vampré sobre a situação, em 1849, na Faculdade de Direito de São Paulo: "Na segunda cadeira (Teoria e Prática do Processo), o lente respectivo está organizando um compêndio, pelo qual explica, aproveitando-se ainda
} 
das doutrinas de Melo Freire, na parte em que são aplicáveis ao estado da nossa legislação.” Ao que tudo indica, pela falta de informações, o titular da cadeira à época, Silveira da Mota, não chegou a redigir o referido compêndio e transferiu-se para a cadeira de direito administrativo. Posteriormente, quando Joaquim Ignácio de Ramalho torna-se o catedrático da cadeira, usará seu livro como compêndio da disciplina.

${ }^{9}$ Tratando da Faculdade de Direito do Recife, assim expõe Bevilaqua: "Em 1855, começou outro período. Logo nesse ano, aparece a Teoria e prática do processo civil, de Paula Batista, e a Faculdade se vai afirmando, como centro apreciável de produção mental." (BEVILAQUA, 1977, p. 303). Mais adiante afirma ser Paula Batista, "incontestavelmente, a figura mais alta da Faculdade de Direito de Recife, antes de Tobias." (p. 311).

${ }^{10}$ Em 1875, no discurso de fundação do Instituto dos Advogados de São Paulo, Ramalho afirmara que: "O estudo do Direito aplicado à vida prática tal é a nossa empresa, tão difícil e trabalhosa quanto dignificante, porque é da exata observância das leis e do respeito inviolável ao Direito que depende, em grande parte, a felicidade dos povos" (OLIVEIRA, 1966, p. 8.)

${ }^{11}$ Optou-se por analisar apenas os julgados em que a discussão de aspectos processuais fosse a questão principal ou determinante no julgamento.

${ }^{12}$ Embora o livro de José Maria Frederico de Souza Pinto (Primeiras linhas sobre processo civil brasileiro) seja considerado repetição da obra do português Pereira e Souza.

${ }^{13}$ Não se diferenciou aqui situações em que o julgado fazia concomitantemente referência a mais de um destes elementos normativos.

${ }_{14}^{14}$ Sobre a forte presença portuguesa nos julgados da época, v.: LOPES, 2002, p. 333-334.

15 Conforme ensina Ricardo Marcelo Fonseca, nessa época "surge a necessidade do elemento "científico" na atividade do jurista. Em outros termos, o jurista deve proceder a sua análise com rigor teórico, nos padrões daquilo que o tempo definia, de maneira forte, como ciência." (FONSECA, 2008, p. 277). V. ainda: LOPES, 2002, p. 341. 